\title{
Fitoextração de cobre por espécies de plantas cultivadas em solução nutritiva
}

\author{
Ariana Carramaschi Francato Zancheta $\left({ }^{1 *}\right)$; Cleide Aparecida de Abreu ( $\left.{ }^{2}\right)$; Fernando \\ César Bachiega Zambrosi ( ${ }^{2}$ ); Norma de Magalhães Erismann (2); Ana Maria Magalhães \\ Andrade Lagôa ( $\left.{ }^{2}\right)$ \\ (') Instituto Agronômico (IAC), Pós-Graduação em Agricultura Tropical e Subtropical, Caixa Postal 28, 13001-970 \\ Campinas (SP), Brasil. \\ (2) IAC, 13001-970 Campinas (SP), Brasil. \\ (*) Autora correspondente: ariri_f@ig.com.br
}

Recebido: 31/maio/2011; Aceito: 5/jul./2011

\begin{abstract}
Resumo
Dentre as tecnologias para remediação de solos contaminados, destaca-se a fitoextração. Uma etapa importante nesta estratégia é a seleção de plantas adequadas para áreas que necessitam de recuperação. O objetivo deste trabalho foi avaliar o potencial fitoextrator de cobre (Cu) por plantas de sorgo (Sorghum bicolor), milheto (Pennisetum glaucum), crotalária (Crotalaria juncea) e feijão-de-porco (Canavalia ensiformis). O delineamento experimental foi em blocos ao acaso e os tratamentos foram constituídos de quatro concentrações de Cu (0,8; 3,9; 19,7 e 98,4 umol L-1) na solução nutritiva. Após 30 dias do início dos tratamentos, foram realizadas medidas de trocas gasosas em folhas completamente expandidas. Em seguida, as plantas foram coletadas, separadas em parte aérea e sistema radicular para avaliação de crescimento e acúmulo de Cu. $\mathrm{O}$ tratamento com 98,4 $\mu \mathrm{mol} \mathrm{L}{ }^{-1}$ de Cu na solução nutritiva inibiu marcadamente o acúmulo de massa seca da parte aérea das raízes das plantas. A condutância estomática, transpiração e assimilação de $\mathrm{CO}_{2}$ não foram alteradas até o tratamento com 19,7 $\mu \mathrm{mol} \mathrm{L} \mathrm{L}^{-1}$ de Cu. O teor e acúmulo de Cu nas plantas foram proporcionais à adição do metal na solução nutritiva, porém, foram muito mais elevados no sistema radicular do que na parte aérea. O acúmulo preferencial de Cu nas raízes, embora diminua o transporte para a parte aérea e contribua para a tolerância das plantas ao metal, é limitante para o emprego da fitoextração. O feijão-de-porco teve maior concentração, acúmulo e transporte de Cu para a parte aérea, sendo uma espécie com potencial para ser utilizada em programas de fitorremediação de Cu.
\end{abstract}

Palavras-chave: descontaminação do solo, Canavalia ensiformis, Pennisetum glaucum, Sorghum bicolor, Crotalaria juncea.

\section{Copper phytoextraction by different plant species grown in nutrient solution}

\section{Abstract}

Among the technologies for remediation of contaminated soils, the phytoremediation is a feasible approach. The first step towards to the implementation of this strategy is the selection of plants with potential to be used in areas that need remediation. The aim of this study was to evaluate the potential for phytoextraction of copper (Cu) by sorghum (Sorghum bicolor), pearl millet (Pennisetum glaucum), crotalaria (Crotalaria juncea) and jack beans (Canavalia ensiformis). The experimental design was in randomized blocks, and treatments consisted of 0.8, 3.9, 19.7 and $98.4 \mu \mathrm{mol} \mathrm{L}^{-1}$ of Cu in the nutrient solution. Thirty days after the beginning of the treatments, the leaf gas exchange was measured in mature leaves. Then, the plants were harvested, separated into shoot and root system for determining dry matter and Cu accumulation. The treatment with $98.4 \mu \mathrm{mol} \mathrm{L-1}$ of Cu markedly impaired shoot and root growth. Stomatal conductance, leaf transpiration rate and net $\mathrm{CO}_{2}$ assimilation were not affected until the treatment with $19.7 \mu \mathrm{mol} \mathrm{L}^{-1}$ of $\mathrm{Cu}$ in the nutrient solution. $\mathrm{Cu}$ content and accumulation in plant tissues were well related to the metal concentration in the nutrient solution, with higher values in the roots than shoots. Although the preferential accumulation of $\mathrm{Cu}$ in the roots and reduced transport to the shoot contribute to enhance plant tolerance to this metal, it limits the use for Cu phytoextraction. Jack bean had the greatest Cu concentration, accumulation and transport of Cu to the shoot. Thus, this plant species has potential to be employed in programs of Cu phytoremediation.

Key words: soil descontamination, Canavalia ensiformis, Pennisetum glaucum, Sorghum bicolor, Crotalaria juncea. 


\section{INTRODUÇÃO}

O cobre $(\mathrm{Cu})$ é um nutriente que atua como componente de várias enzimas e coenzimas, participa da fotossíntese, respiração e do metabolismo de nitrogênio e carboidratos (Fernandes e Henriques, 1991; Yruela, 2009). Entretanto, a presença em altas concentraçōes no solo afeta negativamente o crescimento e a produtividade das plantas (Sonmez et al., 2006), devido aos danos às membranas celulares por meio da peroxidaçáo de lipídios (Bueno e Piqueras, 2002), ao comprometimento da atividade fotossintética (LANARAs et al., 1993) e aos processos de absorção e assimilação de nutrientes (Llorens et al., 2000; Devriese et al., 2001). Em solos agrícolas, um dos principais fatores relacionados ao aumento do teor de $\mathrm{Cu}$ em níveis fitotóxicos é a utilização intensiva de fungicidas cúpricos (Pietrzak e McPhail, 2004; Mirlean et al., 2007). Este cenário cria a necessidade de que sejam disponibilizadas estratégias para a recuperaçáo desses locais, ou a minimização dos impactos ambientais oriundos da contaminação.

A utilização de plantas para a recuperação de áreas contaminadas, técnica conhecida como fitorremediação, tem se popularizado e surgido como alternativa viável, uma vez que é considerada de baixo custo, promove a manutenção da fertilidade do solo, além de ter como principal fonte de energia a luz solar (RoBinson et al., 2003). Dentro da fitorremediação, a capacidade das plantas em extrair os metais do solo e acumulá-los preferencialmente na parte aérea, é denominada fitoextração (NASCimento e XING, 2006). Embora, a avaliação da tolerância e a capacidade de extração de metais por diferentes espécies de plantas tenham sido intensificadas (Jiang et al., 2004; SiLVA et al., 2006; XIa e Shen, 2007; WAng et al., 2009; SAntos et al., 2010), ainda existe a necessidade de ampliar o conjunto de espécies avaliadas para o emprego em programas de fitorremediação de $\mathrm{Cu}$. Nesse contexto, devido à maior facilidade de propagação e cultivo, seria importante que as plantas cultivadas em áreas agrícolas fossem avaliadas quanto ao grau de tolerância e como possíveis candidatas à fitoextração de metais pesados.

Diante do exposto, o presente trabalho teve por objetivo avaliar o potencial de fitoextração de $\mathrm{Cu}$ por diferentes espécies de plantas cultivadas em condiçôes de solução nutritiva.

\section{MATERIAL E MÉTODOS}

O experimento foi desenvolvido em casa de vegetação (modelo capela com cobertura e laterais de vidro, contendo janelas zenitais laterais e na cumeeira), localizada no município de Campinas-SP, durante o verão, com temperaturas médias correspondentes a $37^{\circ}( \pm 3,0)$ e $15^{\circ}( \pm 1,5)$ para máxima e mínima, respectivamente. As espécies utilizadas corresponderam ao milheto (Pennisetum glaucum cv. BRS 1501), sorgo (Sorghum bicolor cv. Vassoura), crotalária (Crotalaria juncea cv. Juncea) e feijão-de-porco (Canavalia ensiformis) e cada uma constituiu um experimento independente.

As plantas foram submetidas às concentrações de $\mathrm{Cu}$ na solução nutritiva equivalentes a 0,$8 ; 3,9 ; 19,7 \mathrm{e}$ $98,4 \mu \mathrm{mol} \mathrm{L}-1$, na forma de sulfato de cobre $\left(\mathrm{Cu}_{2} \mathrm{SO}_{4} .5\right.$ $\left.\mathrm{H}_{2} \mathrm{O}\right)$. O tratamento controle de $\mathrm{Cu}\left(0,8 \mu \mathrm{mol} \mathrm{L}^{-1}\right.$ de $\mathrm{Cu}$ ) foi embasado na sugestão apresentada por Furlani e Furlani (1988) para o cultivo de plantas em solução nutritiva. As demais concentraçôes foram estabelecidas com o objetivo de verificar as respostas destas plantas ao suprimento crescente do metal. A solução nutritiva básica tinha a seguinte composição, em mmol L-1: $11,4 \mathrm{~N}\left(11 \%\right.$ como $\left.\mathrm{NH}_{4}^{+}\right) ; 0,1 \mathrm{P} ; 2,2$ $\mathrm{K}$; 3,5 Ca; 0,9 Mg; 0,5 S; em $\mu \mathrm{mol} \mathrm{L}^{-1}$ : 53,7 Fe; 7,1 Mn; 2,8 Zn; 20,4 B e 0,6 Mo (Furlani e Furlani, 1988). O delineamento experimental foi em blocos ao acaso, com três repetiçóes, totalizando 12 parcelas em cada experimento. A parcela foi constituída por dois recipientes plásticos de 1,6 L de capacidade, contendo duas plantas em cada um.

As plântulas foram obtidas a partir da germinação das sementes em bandejas plásticas contendo uma mistura de areia lavada e vermiculita na proporção de $2: 1$, com prévia desinfecção das sementes em solução de hipoclorito de sódio a $1 \%$ durante 5 minutos e posterior lavagem com água corrente. Após 10-12 dias da germinação, ou quando as plântulas estavam com dois pares de folhas, foram transplantadas para solução nutritiva diluída a $1 / 4$ daquela usada para o cultivo. Após cinco dias de crescimento em solução nutritiva diluída, substituiu-se por uma solução completa contendo as diferentes concentrações de $\mathrm{Cu}$. Durante o manejo do experimento, a solução nutritiva foi renovada a cada 10 dias e o nível inicial foi mantido constante com a adição diária de água deionizada. $\mathrm{O}$ pH foi ajustado para próximo de 5,0 e o meio de crescimento radicular foi aerado constantemente com auxílio de um compressor de ar.

Após 30 dias de cultivo sob os tratamentos de $\mathrm{Cu}$, as plantas foram coletadas, separando-se a parte aérea (PA) do sistema radicular (SR). Estas partes foram lavadas em água deionizada e colocadas para secar em estufa a $70{ }^{\circ} \mathrm{C}$ com circulação forçada de ar, por 72 horas. O material vegetal foi pesado para obtenção da massa seca (MS) da PA e do SR, e moído em moinho tipo Willey. A concentração de $\mathrm{Cu}$ e demais elementos no tecido vegetal foi determinada por espectrometria de emissão por plasma ICP-OES após digestão nitroperclórica (BATAGLia et al., 1983). A partir do produto entre as concentraçóes de $\mathrm{Cu}$ com a MS da PA e do SR obteve-se o acúmulo do metal nas plantas. O transporte (\%) de Cu para a PA foi calculado mediante a relação entre a quantidade total de $\mathrm{Cu}$ acumulada na $\mathrm{PA}$ e na planta inteira. 
No dia da coleta das plantas, das 9 às $11 \mathrm{~h}$, em folhas completamente expandidas, foi medida a assimilação de $\mathrm{CO}_{2}\left(A_{\mathrm{CO} 2}\right)$, a condutância estomática $\left(\mathrm{g}_{\mathrm{s}}\right)$, a transpiração (E) e a concentração intercelular de $\mathrm{CO}_{2}\left(\mathrm{C}_{\mathrm{i}}\right)$, utilizandose um analisador portátil de gases IRGA (Infra Red Gas Analyser, Li-6400, Li-Cor inc., Lincoln, NE, USA). A temperatura da câmara de medida foi ajustada para aquela vigente dentro da casa de vegetaçáo no momento das medidas $\left(28^{\circ} \mathrm{C}\right)$ e a densidade de fluxo de fótons fotossinteticamente ativos foi ajustada em $1600 \mu \mathrm{mol} \mathrm{m}^{-2} \mathrm{~s}^{-1}$, enquanto a diferença de pressão de vapor entre a folha e o ar permaneceu entre 1,0 e 1,5 kPa. Devido à insuficiência de área foliar da crotalária, milheto e sorgo para preencher a área útil da câmara de medida $\left(6 \mathrm{~cm}^{2}\right)$, as trocas gasosas não foram realizadas no tratamento com $98,4 \mu \mathrm{mol} \mathrm{L}^{-1} \mathrm{de}$ Cu na solução nutritiva.

Os resultados foram submetidos à análise de variância $\mathrm{e}$, no caso de teste $\mathrm{F}$ significativo $(\mathrm{p}<0,05)$, o efeito da concentraçáo de $\mathrm{Cu}$ na solução nutritiva para cada espécie de planta foi avaliado utilizando-se o teste de Tukey a 5\%. A comparação entre as espécies ou entre PA e SR dentro do mesmo tratamento de $\mathrm{Cu}$ foi realizada com base na média \pm erro-padrão $(n=3)$.

\section{RESULTADOS E DISCUSSÃO}

O acúmulo de MS na PA por plantas de milheto e de feijão-de-porco no tratamento com 19,7 $\mu \mathrm{mol} \mathrm{L}^{-1}$ de $\mathrm{Cu}$ na solução nutritiva foi reduzido em $60 \%$ e $30 \%$ respectivamente, em comparação ao controle $\left(0,8 \mu \mathrm{mol} \mathrm{L}^{-1} \mathrm{de}\right.$ $\mathrm{Cu}$ ) (Figura 1). Por outro lado, nas plantas de sorgo e crotalária, a redução deste parâmetro ocorreu somente quando foram cultivadas na maior concentração do metal $\left(98,4 \mu \mathrm{mol} \mathrm{L}{ }^{-1}\right)$. Nesse tratamento, o decréscimo na MS em relação ao controle correspondeu a $89 \%$ para crotalária, $83 \%$ para o feijāo-de-porco, $97 \%$ para sorgo e $99 \%$ no caso do milheto (Figura 1). A variação no grau de redução do crescimento dessas plantas confirmou a ocorrência de diferenças na tolerância ao excesso de $\mathrm{Cu}(\mathrm{KE}$ et al., 2006; Xia e Shen, 2007), o que tem sido associada por exemplo, ao nível de atividade das enzimas que atuam na desintoxicação de radicais livres ( Devi e Prassad, 1998; Li et al., 2009) e na redução da toxicidade do metal após quelação por compostos orgânicos e/ou compartimentalização no vacúolo (Hall, 2002; Qian et al., 2005). O efeito do $\mathrm{Cu}$ sobre o acúmulo de MS do SR seguiu praticamente o mesmo padrão observado para a PA (Figura 1), embora o $\mathrm{Cu}$ deva inibir de forma mais drástica o crescimento das raízes (QIAN et al., 2005), levando à redução da relação raiz:parte aérea. Entretanto, esse efeito não foi suportado nesta pesquisa, uma vez que não houve maior acúmulo relativo de MS na $\mathrm{PA}$ em detrimento às raízes com a adição de $\mathrm{Cu}$ na soluçấo nutritiva (dados não mostrados). A reduçáo do crescimento radicular na presença
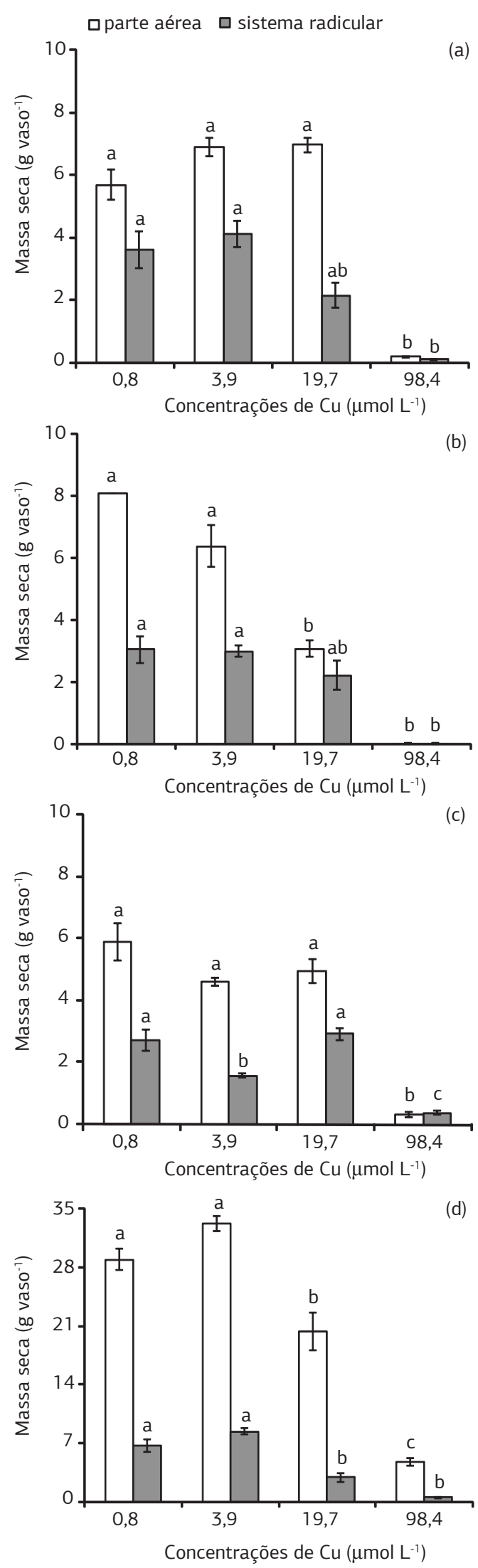

Figura 1. Massa seca da parte aérea e do sistema radicular de plantas de sorgo (a), milheto (b), crotalária (c) e feijão-de-porco (d) cultivadas em solução nutritiva. Colunas com letras iguais para mesma espécie e parte da planta náo diferem pelo teste de Tukey a $5 \%$. As barras verticais indicam o erro-padrão da média $(\mathrm{n}=3)$. 
de $98,4 \mu \mathrm{mol} \mathrm{L}^{-1}$ de $\mathrm{Cu}$ foi associada à ocorrência de raízes com coloraçáo escurecida, o que tem sido descrito como sintoma típico da toxicidade por $\mathrm{Cu}$ (Heale e Ormrod, 1982; Mourato et al., 2009).

$\mathrm{O}$ efeito prejudicial de altas concentrações de $\mathrm{Cu}$ no ambiente radicular sobre o crescimento das plantas também tem sido relacionado ao comprometimento na absorção e metabolismo de nutrientes (WeBER et al., 1991; LLORENs et al., 2000). No presente estudo, correlaçôes negativas entre os teores $\mathrm{Cu}$ com o $\mathrm{Zn}(\mathrm{r}=-0,75 ; \mathrm{p}=0,020$; $\mathrm{n}=12)$ e $\mathrm{Ca}(\mathrm{r}=-0,74 ; \mathrm{p}=0,023)$ foram obtidas na $\mathrm{PA}$ do sorgo. Para o feijão-de-porco, o teor de $\mathrm{Cu}$ foi negativamente correlacionado com $\mathrm{Ca}(\mathrm{r}=-0,70 ; \mathrm{p}=0,034$; $\mathrm{n}=12)$ e com o Fe $(\mathrm{r}=-0,96 ; \mathrm{p}<0,0001 ; \mathrm{n}=12)$, o que tem sido atribuído à competição por sítios de absorção na superfície radicular (MARSCHNER, 1995). Desta maneira, os sintomas típicos da deficiência de Fe (clorose internerval nas folhas) no tratamento com $98,4 \mu \mathrm{mol} \mathrm{L}^{-1}$ de $\mathrm{Cu}$ resultou da diminuição na absorção e no transporte de $\mathrm{Fe}$ para a PA e da concentraçáo de clorofila (PÄTsıKKä et al., 2002). Por outro lado, Mourato et al. (2009) náo verificaram alteração na concentração de $\mathrm{Ca} e \mathrm{Fe}$, mas apenas para a de $\mathrm{Zn}$ na PA de plantas de tremoço (Lupinus luteus L.) submetidas a 0,1-50 $\mu \mathrm{mol} \mathrm{L}^{-1}$ de $\mathrm{Cu}$ na solução nutritiva. XIA e SHen (2007) observaram que as concentraçóes de 50 e $100 \mu \mathrm{mol} \mathrm{L}^{-1}$ de $\mathrm{Cu}$ reduziram os teores de $\mathrm{Fe}$ e Zn na PA de três espécies de Elshotzia (E. haichowensis, E. cypriani e $E$. ciliata), enquanto que para os teores de $\mathrm{Ca}$, o efeito de excesso de $\mathrm{Cu}$ não ocorreu para E.haichowensis. Esses resultados, de certo modo, corroboram com aqueles avaliados no presente estudo, em que o efeito do $\mathrm{Cu}$ sobre a concentração dos nutrientes na PA foi variável entre as plantas testadas.

Os teores de Cu na PA e SR das plantas foram proporcionais à concentração do metal na soluçáo nutritiva, tendo-se incrementos mais acentuados no SR do que na PA (Figura 2). Por exemplo, na média das espécies, a faixa de variaçáo no teor de $\mathrm{Cu}$ entre o tratamento controle e aquele com 19,7 $\mu \mathrm{mol} \mathrm{L} \mathrm{L}^{-1}$ de $\mathrm{Cu}$ correspondeu a $15-30 \mathrm{mg} \mathrm{kg}^{-1}$ na PA e $74-617 \mathrm{mg} \mathrm{kg}^{-1}$ no SR. A concentração mais elevada de Cu no SR é consistente com resultados encontrados em outros estudos (WeBER et al., 1991; Jiang et al., 2004; Xia e Shen, 2007), o que tem sido relacionado ao baixo transporte do metal para a PA. A retenção de $\mathrm{Cu}$ nas raízes é um mecanismo de tolerância ao excesso do metal, ocorrendo, por exemplo, a imobilização do metal na parede celular por carboidratos extracelulares, e consequentemente, a reduzida presença de íons livres para transporte à PA (LASAT, 2002).

Em concordância com os resultados de teor, o acúmulo de $\mathrm{Cu}$ no SR, principalmente nos tratamentos com 19,7 e $98,4 \mu \mathrm{mol} \mathrm{L}^{-1}$ de $\mathrm{Cu}$, foi muito mais elevado do que na PA (Figura 3). O feijão-de-porco foi a planta mais eficiente na extração de $\mathrm{Cu}$, uma vez que tinha maior acúmulo do metal na PA, variando entre 744 e $1491 \mu \mathrm{g}$ vaso $^{-1}$ 口parte aérea $\square$ sistema radicular

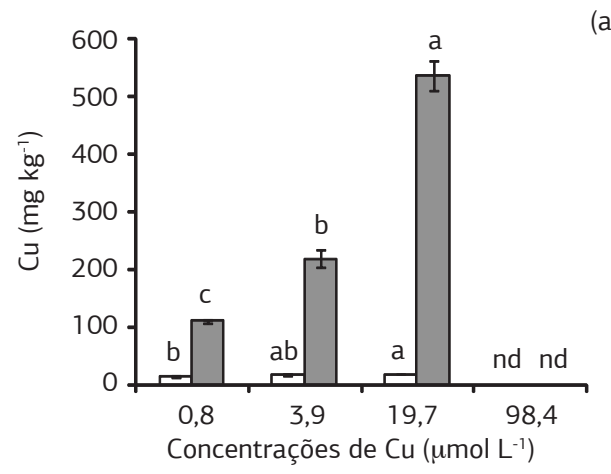

(a)

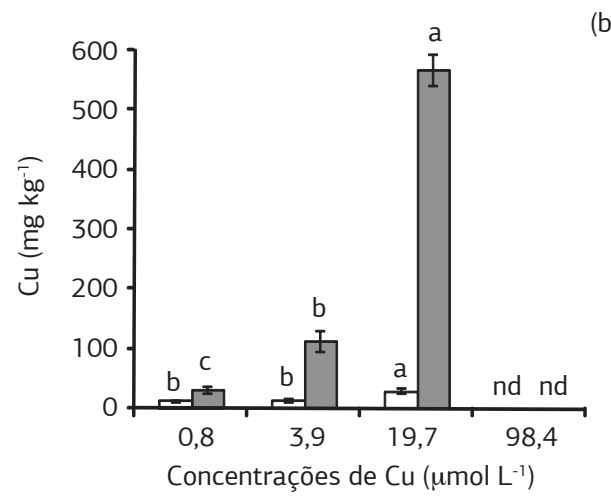

(c)

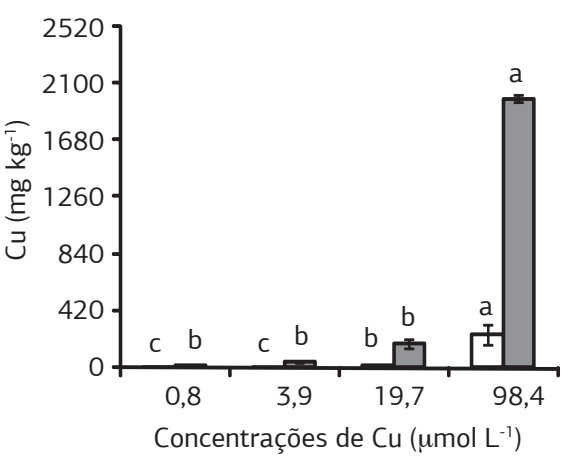

(b)

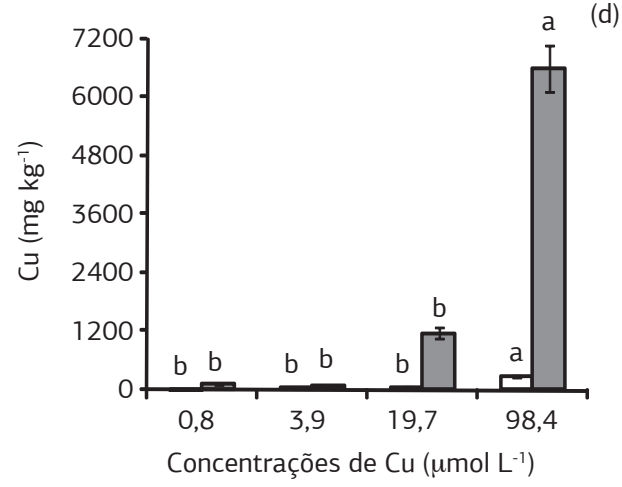

Figura 2. Teor de cobre $(\mathrm{Cu})$ na parte aérea e sistema radicular de plantas de sorgo (a), milheto (b), crotalária (c) e feijāo-de-porco (d) cultivadas em soluçáo nutritiva. Colunas com letras iguais para mesma espécie e parte da planta não diferem pelo teste de Tukey a 5\%. As barras verticais indicam o erro-padrão da média $(\mathrm{n}=3)$. nd = não determinado. 
para os tratamentos de $\mathrm{Cu}$ na soluçáo nutritiva (Figura 3). Andrade et al. (2010), trabalhando com a mesma espécie em solo que recebeu quantidades crescentes de $\mathrm{Cu}$, também verificaram potencial fitoextrator. De acordo com os autores, a habilidade do feijão-de-porco em acumular o $\mathrm{Cu}$ foi relacionada à produção de fitoquelatinas no tecido foliar, que reduzem a concentraçáo de metal livre no citosol, limitando sua solubilidade e reatividade (LASAT, 2002; Olrva et al., 2010). Uma característica desejável das plantas fitoextratoras é a capacidade de transporte do elemento absorvido pelas raízes para a PA (JABEEN et al., 2009), uma vez que esta será a parte preferencial e mais facilmente removida da área que está sendo remediada. Nesse contexto, exceto no tratamento com $0,8 \mu \mathrm{mol} \mathrm{L}^{-1} \mathrm{de} \mathrm{Cu}$, entre as espécies estudadas foram observadas no feijão-de-porco as maiores taxas de transporte do metal para a PA (Figura 4), enquanto o sorgo caracterizou-se como a planta menos eficiente neste processo (Figura 4), o que poderia limitar seu emprego em programas de fitorremediaçáo com o uso da fitoextração. É importante destacar, também, que o milheto proporcionou a reduçáo mais acentuada no transporte de $\mathrm{Cu}$ para PA mediante a adiçáo do metal na solução nutritiva, enquanto para crotalária e feijão-de-porco, ocorreu em menor proporção (Figura 4). A baixa taxa de transporte do $\mathrm{Cu}$ para PA (entre 10 e $25 \%$ ) também foi verificada por SoAREs et al. (2000) ao trabalharem com duas espécies de eucaliptos (Eucalyptus maculata e Eucalyptus urophylla), submetidas à presença de 0 a $192 \mu \mathrm{mol} \mathrm{L}^{-1}$ de Cu na soluçáo nutritiva. Deste modo, embora a maior retenção de $\mathrm{Cu}$ nas raízes e, consequentemente, menor transporte para a PA seja um importante mecanismo de tolerância das plantas a concentraçôes excessivas do metal, esse processo será, ao mesmo tempo, um fator limitante para o emprego da técnica da fitoextração para a remediação de áreas contaminadas com $\mathrm{Cu}$.

A $A_{\mathrm{CO} 2}, \mathrm{~g}_{\mathrm{s}}$ e $\mathrm{E}$ das espécies estudas foram similares ao controle até o tratamento com 19,7 $\mu \mathrm{mol} \mathrm{L}^{-1} \mathrm{de} \mathrm{Cu}$ na solução nutritiva (Tabela 1). Em relação ao $\mathrm{C}_{\mathrm{i}}$, apenas no sorgo foi detectada redução deste parâmetro para esta mesma concentração de $\mathrm{Cu}$ na solução nutritiva. Entretanto, esse fato não foi associado à diminuição da $\mathrm{g}_{\varsigma}$ ou alteração na $A_{\mathrm{CO} 2}$. A ausência de variação na $A_{\mathrm{CO} 2}$ para o sorgo e para a crotalária foi condizente com pequena alteração no crescimento destas plantas quando submetidas às concentraçôes de $\mathrm{Cu}$ na solução nutritiva variando entre 0,8 e $19,7 \mu \mathrm{mol} \mathrm{L}^{-1}$. O mesmo não foi observado para o milheto e feijão-de-porco, que tiveram o crescimento diminuído, embora a $A_{\mathrm{CO} 2}$ no tratamento 19,7 $\mu \mathrm{mol} \mathrm{L}^{-1}$ de $\mathrm{Cu}$ tenha sido semelhante ao do controle (Figura 1). É possível que a necessidade de reparo aos danos causados pela açáo tóxica de metais, ocasionando maior consumo de energia pelas plantas (degradaçáo de carbono pela respiração) (PRASAD et al., 2001), tenha contribuído para comprometer o crescimento. Embora, o efeito do tratamento com $98,4 \mu \mathrm{mol} \mathrm{L}^{-1} \mathrm{de} C \mathrm{Cu}$ sobre os parâmetros fotossintéticos não tenha sido determinado para

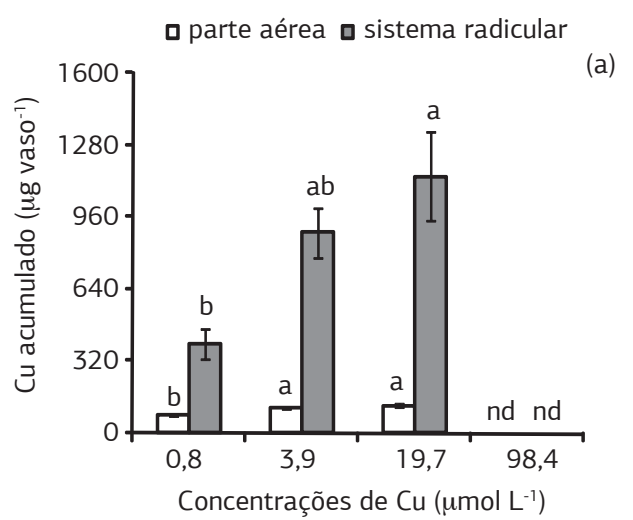

(a)

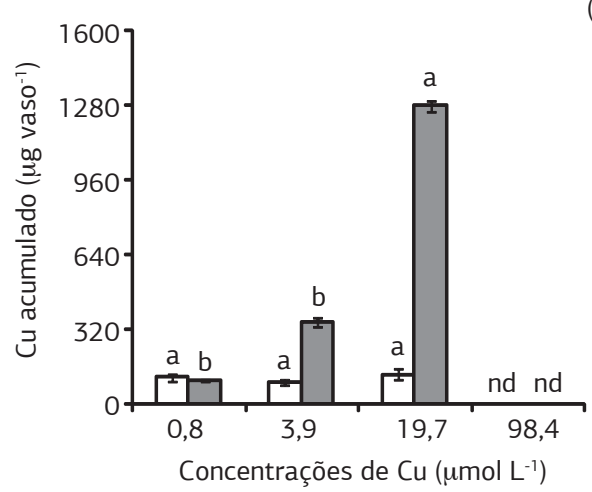

(b)

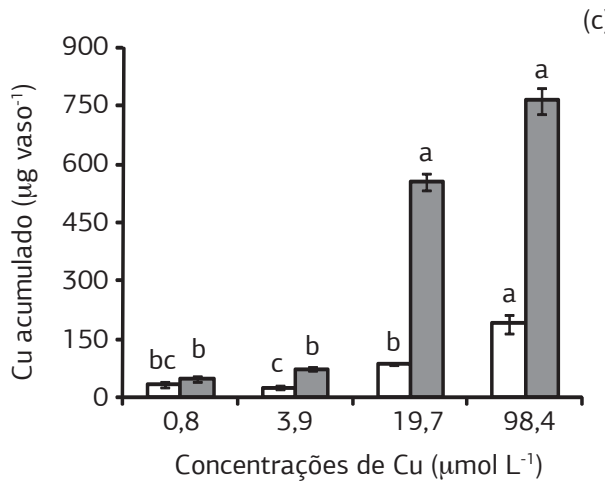

(c)

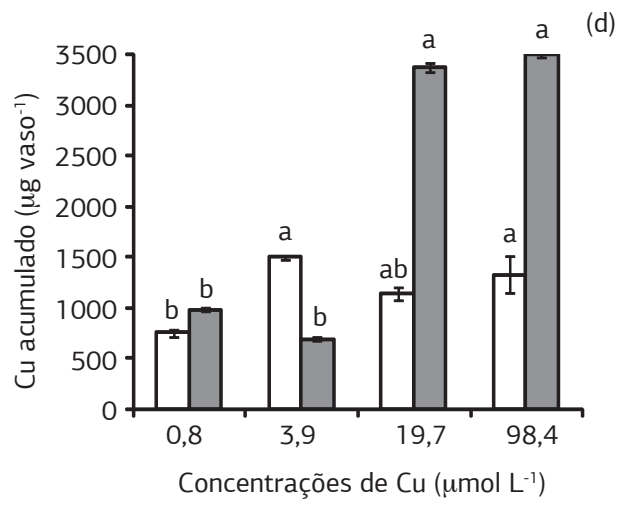

Figura 3. Acúmulo de cobre $(\mathrm{Cu})$ na parte aérea e sistema radicular de plantas de sorgo (a), milheto (b), crotalária (c) e feijão-de-porco (d) cultivadas em solução nutritiva. Colunas com letras iguais para mesma espécie e parte da planta não diferem pelo teste de Tukey a $5 \%$. As barras verticais indicam o erro-padrão da média $(n=3)$. nd = não determinado. 

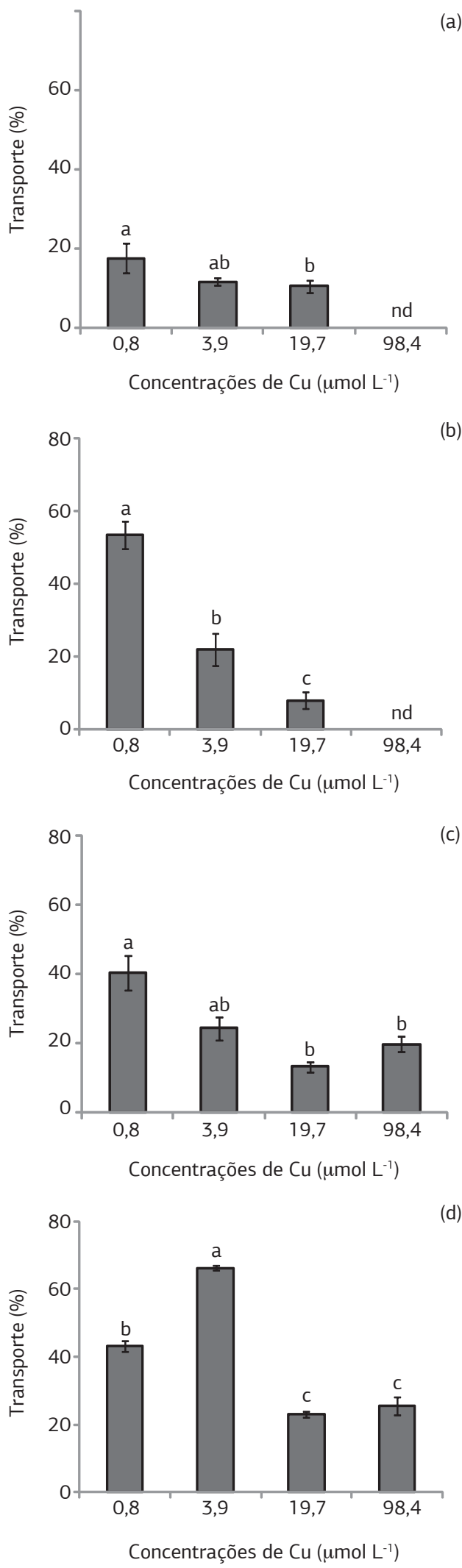

Figura 4. Transporte de cobre para a parte aérea de plantas de sorgo (a), milheto (b), crotalária (c) e feijão-de-porco (d) cultivadas em solução nutritiva. Colunas com letras iguais para mesma espécie não diferem pelo teste de Tukey a $5 \%$. As barras verticais indicam o erro-padrão da média $(\mathrm{n}=3)$. nd = não determinado. milheto, sorgo e crotalária devido à insuficiência de área foliar, decréscimos na $A_{\mathrm{CO} 2}, \mathrm{~g}_{\mathrm{s}}, \mathrm{E}$ e $\mathrm{C}_{\mathrm{i}}$ em relaçáo ao controle foram observados para feijão-de-porco (Tabela 1). A ação prejudicial do excesso de $\mathrm{Cu}$ sobre a fotossíntese tem sido associada à redução dos teores de clorofila (XIONG et al., 2006), ao comprometimento no transporte de elétrons (Yruela et al., 2000) e ao efeito inibitório sobre as enzimas do ciclo de Calvin (Ouzounidou e Ilias, 2005).

Tabela 1. Assimilação de $\mathrm{CO}_{2}\left(A_{\mathrm{CO} 2}\right)$. condutância estomática $\left(\mathrm{g}_{\mathrm{s}}\right)$, transpiração $(\mathrm{E})$ e concentração intercelular $\left(\mathrm{C}_{\mathrm{i}}\right)$ de $\mathrm{CO}_{2}$ em plantas de crotalária, milheto, feijão-de-porco e sorgo cultivadas em solução nutritiva com diferentes concentraçốes de $\mathrm{Cu}$

\begin{tabular}{|c|c|c|c|c|}
\hline $\begin{array}{l}\text { Concentrações } \\
\text { de } \mathrm{Cu}\end{array}$ & Sorgo & Milheto & Crotalária & $\begin{array}{l}\text { Feijão- } \\
\text { de-porco }\end{array}$ \\
\hline$\left(\mu \mathrm{mol} \mathrm{L} \mathrm{L}^{-1}\right)$ & \multicolumn{4}{|c|}{$A_{\mathrm{CO} 2}\left(\mu \mathrm{mol} \mathrm{m}{ }^{-2} \mathrm{~s}^{-1}\right)$} \\
\hline 0,8 & $9,5 \mathrm{a}$ & $18,0 \mathrm{a}$ & $16,2 \mathrm{a}$ & $11,7 \mathrm{a}$ \\
\hline 3,9 & $8,8 \mathrm{a}$ & $18,5 \mathrm{a}$ & $20,3 \mathrm{a}$ & $10,6 a b$ \\
\hline 19,7 & $14,3 \mathrm{a}$ & $16,0 \mathrm{a}$ & $12,8 \mathrm{a}$ & $11,8 \mathrm{a}$ \\
\hline \multirow[t]{2}{*}{98,4} & nd & nd & nd & $3,9 \mathrm{~b}$ \\
\hline & \multicolumn{4}{|c|}{$\mathrm{g}_{\mathrm{s}}\left(\mathrm{mol} \mathrm{m} \mathrm{m}^{-2} \mathrm{~s}^{-1}\right)$} \\
\hline 0,8 & $0,10 \mathrm{a}$ & $0,13 \mathrm{a}$ & $0,54 \mathrm{a}$ & $0,31 \mathrm{a}$ \\
\hline 3,9 & $0,10 a$ & $0,14 \mathrm{a}$ & $0,49 a$ & $0,23 \mathrm{ab}$ \\
\hline 19,7 & $0,13 a$ & $0,10 \mathrm{a}$ & $0,36 \mathrm{a}$ & $0,28 \mathrm{ab}$ \\
\hline \multirow[t]{2}{*}{98,4} & nd & nd & nd & $0,05 b$ \\
\hline & \multicolumn{4}{|c|}{$\mathrm{E}\left(\mathrm{mmol} \mathrm{m} \mathrm{m}^{-2} \mathrm{~s}^{-1}\right)$} \\
\hline 0,8 & $1,5 \mathrm{a}$ & $1,87 \mathrm{a}$ & $3,87 \mathrm{a}$ & $3,7 \mathrm{a}$ \\
\hline 3,9 & $1,5 \mathrm{a}$ & $1,95 \mathrm{a}$ & $4,36 \mathrm{a}$ & $3,1 \mathrm{ab}$ \\
\hline 19,7 & $1,9 \mathrm{a}$ & $1,56 \mathrm{a}$ & $3,00 \mathrm{a}$ & $3,5 \mathrm{a}$ \\
\hline \multirow[t]{2}{*}{98,4} & nd & nd & nd & $0,9 \mathrm{~b}$ \\
\hline & \multicolumn{4}{|c|}{$C_{i}\left(\mu \mathrm{mol} \mathrm{mol}^{-1}\right)$} \\
\hline 0,8 & $190 \mathrm{a}$ & $100 \mathrm{a}$ & $226 \mathrm{a}$ & $287 a$ \\
\hline 3,9 & $200 \mathrm{a}$ & $108 \mathrm{a}$ & $244 a$ & $276 a b$ \\
\hline 19,7 & $156 b$ & $79 \mathrm{a}$ & $196 \mathrm{a}$ & $278 a b$ \\
\hline 98,4 & nd & nd & nd & $244 b$ \\
\hline
\end{tabular}

Médias seguidas por letras iguais na mesma coluna năo diferem pelo teste de Tukey a $5 \%$. nd = não determinado (área foliar insuficiente).

\section{CONCLUSÃO}

$\mathrm{O} \mathrm{Cu}$ foi acumulado preferencialmente no sistema radicular e, portanto, translocado em baixa proporçáo para a parte aérea, o que embora seja considerada uma estratégia das plantas para aumentar a tolerância ao metal, será limitante para o emprego da fitoextração. O maior potencial de transporte do metal para a PA foi observado em feijãode-porco, o que em conjunto com a alta concentração de $\mathrm{Cu}$ na parte aérea e acúmulo do metal, faz com que essa espécie tenha potencial para ser utilizada em programas de fitoextração de $\mathrm{Cu}$.

\section{AGRADECIMENTO}

À Fundação de Apoio à Pesquisa do Estado de São Paulo - FAPESP, pela concessão da bolsa de pesquisa. 


\section{REFERÊNCIAS}

ANDRADE, S.A.L.; GRATÃO, P.L.; SCHIAVINATO, M.A.; SILVEIRA, A.P.D.; AZEVEDO, R.A.; MAZZAFERA, P. Biochemical and physiological changes in jack bean under mycorrhizal symbiosis growing in soil with increasing $\mathrm{Cu}$ concentrations. Environmental and Experimental Botany, v.68, p.198-207, 2010.

BATAGLIA, O.C.; FURLANI, A.M.C.; TEIXEIRA, J.P.F.; FURLANI, P.R.; GALLO, J.R. Método de análise química de plantas. Campinas: Instituto Agronômico, 1983. 48p. (Boletim técnico n.78)

BUENO, P.; PIQUERAS, A. Effect of transition metals on stress, lipid peroxidation and antioxidant enzyme activites in tobacco cell cultures. Plant Growth Regulation, v.36, p.161-167, 2002.

DEVI, S.R.; PRASAD, M.N.V. Copper toxicity in Ceratophyllum demersum L. (Coontail), a free floating macrophyte: Response of antioxidant enzymes and antioxidants. Plant Science, v.138, p.157165,1998

DEVRIESE, M.; TSAKALOUDIB, V.; GARBAYOC, I.; LEÓNC, R.; VILCHEZEC, C.; VIGARAC, J. Effect of heavy metals on nitrate assimilation in the eukaryotic microalga Chlamydomonas reinhardtii. Plant Physiology and Biochemistry, v.39, p.443-448, 2001.

FERNANDES, J.C.; HENRIQUES, F.S. Biochemical, physiological and structural effects of excess copper in plants. The Botanical Review, v.57, p.246-273, 1991.

FURLANI, A.M.C.; FURLANI, P.R. Composição e pH de soluçóes nutritivas para estudos fisiológicos e seleção de plantas em condiçóes nutricionais adversas, Campinas: Instituto Agronômico, 1988. 34p. (Boletim técnico, 121)

HALL, J.L. Cellular mechanisms for heavy metal detoxification and tolerance. Journal of Experimental Botany, v.53, p.1-11, 2002.

HEALE, E.L.; ORMROD D.P. Effects of nickel and copper on Acer rubrum, Cornus stolonifera, Lonicera tatarica and Pinus resinosa. Canadian Journal of Botany, v.60, p. 2674-2681, 1982.

JABEEN, R.; AHMAD, A.; IQBAL, M. Phytoremediation of heavy metals: physiological and molecular mechanisms. The Botanical Review, v.75, p.339-364, 2009.

JIANG, L.Y.; YANG, X.E.; HE, Z.L. Growth response and phytoextraction of copper at different levels in soils by Elsholtzia splendens. Chemosphere, v.55, p.1179-1187, 2004.

KE, W.; XIONG, Z.T.; CHEN, S.; CHEN, J. Effects of copper and mineral nutrition on growth, copper accumulation and mineral element uptake in two Rumex japonicus populations from a copper mine and an uncontaminated field sites. Environmental and Experimental Botany, v.59, p.59-67, 2006.

LANARAS, T.; MOUSTAKAS, M.; SYMEONIDIS, L.; DIAMANTOGLOU, S.; KARATAGLIS, S. Plant metal content, growth responses and some photosynthetic measurements on fieldcultivated wheat growing on ore bodies enriched in $\mathrm{Cu}$. Physiologia Plantarum, v.88, p.307-314, 1993.
LASAT, M.M. Phytoextraction of toxic metals: a review of biological mechanisms. Journal of Environmental Quality, v.31, p.109-120, 2002.

LI, Y.M.; CHANEY, R.L.; ANGLE, J.S.; BAKER, A.J.M. Phytoremediation of heavy metal contaminated soils. In: Wise, D.L. (Ed.). Bioremediation of contaminated soils. Marcel Dekker, New York, 2009.

LLORENS, N.; AROLA, L.; BLADÉ, C.; MAS, A. Effects of copper exposure upon nitrogen metabolism in tissue cultured Vitis vinifera. Plant Science, v.160, p.159-163, 2000.

MARSCHNER, H. Mineral Nutrition of Higher Plants. 2.ed. San Diego, CA, USA: Academic Press, 1995. 902p.

MIRLEAN, N.; ROISENBERG, A.; CHIES, J.O. Metal contamination of vineyard soils in wet subtropics (southern Brazil). Environmental Pollution, v.149, p.10-17, 2007.

MOURATO, M.P.; MARTINS, L.L.; CAMPOS-ANDRADA, M.P. Physiological responses of Lupinus luteus to different copper concentrations. Biologia Plantarum, v.53, p.105-111, 2009.

NASCIMENTO, C.W.A.; XING, B. Phytoextraction: a review on enhanced metal availability and plant accumulation. Scientia Agricola, v.63, p.299-311, 2006.

OUZOUNIDOU, G.; ILIAS, I. Hormone-induced protection of sunflower photosynthetic apparatus against copper toxicity. Biologia Plantarum, v.49, p.223-228, 2005.

OLIVA, S.R.; MINGORANCE, M.D.; VALDÉS, B.; LEIDI, E.O. Uptake, localization and physiological changes in Erica andevalencis. Plant and Soil, v.328, p.411-420, 2010.

PÄTSIKKÄ, E.; KAIRAVUO, M.; ŠERŠEN, F.; ARO, E.M.; TYYSTJÄRVI, E. Excess of copper predisposes photosystem II to photoinhibition in vivo outcompeting iron and causing decrease in leaf chlorophyll. Plant Physiology, v.129, p.13591367, 2002.

PIETRZAK, U.; McPHAIL, D.C. Copper accumulation, distribution and fractionation in vineyard soils of Victoria, Australia. Geoderma, v.122, p.151-166, 2004.

QIAN, M.; LI, X.; SHEN, Z. Adaptative copper tolerance in Elsholtzia haichowensis involves the production of $\mathrm{Cu}$-induced thiol peptides. Plant Growth Regulation, v.47, p. 65-73, 2005.

PRASAD, M.N.V.; MALEC, P.; WALOSZEK A.; BOJKO, M.; STRZALKA, K. Physiological responses of Leman trisulca L. (duckweed) to cadmium and copper bioaccumulation. Plant Science, v.161, p.881-889, 2001.

ROBINSON, B.; FERNANDEZ, J.E.; MADEJÓN, P.; MARAN̂HÓN, T.; MURILLO, J.M.; GREEN, S.; BRENT, C. Phyotoextraction: an assessment of biochochemical and economic viability. Plant and Soil, v.249, p.117-125, 2003.

SANTOS, G.C.G.; RODELLA, A.A.; ABREU, C.A.; COSCIONE, A.R. Vegetable species for phytoextraction of boron, copper, lead, manganese and zinc from contaminated soil. Scientia Agricola, v.67, p.713-719, 2010. 
SILVA, S.; SIQUEIRA, J.O.; SOARES, C.R.F. Fungos micorrízicos no crescimento e na extração de metais pesados pela braquiária em solo contaminado. Pesquisa Agropecuária Brasileira, v. 41, p.17491757, 2006.

SOARES, C.R.F.S.; SIQUEIRA, J.O.; CARVALHO, J.G; MOREIRA, F.M.S. Crescimento e nutrição mineral de Eucalyptus maculata e Eucapyptus urophylla em solução nutritiva com concentração crescente de cobre. Revista Brasileira de Fisiologia Vegetal, v.12, p.213-225, 2000.

SONMEZ, S.; KAPLAN, M.; SONMEZ, N.K.; KAYA, H.; UZ, I. High Level of Copper application to soil and leaves reduce the growth and yield of tomato plants. Scientia Agricola, v.63, p.213$218,2006$.

WANG, Y.; ZHANG, L.; YAO, J.; HUANG, Y.; YAN, M. Accumulation and Resistance to Copper of Two Biotypes of Cynodon dactylon. Bulletin of Environmental Contamination and Toxicology, v.82, p.454-459, 2009.
WEBER, M.B.; SCHAT, H.; TEN BOOKMUN DER MAAREL. W.M. The effect of copper toxicity on the contents of nitrogen compounds in Silene vulgaris (Moench) Garcke. Plant and Soil, v.133, p.101-109, 1991.

XIA, Y.; SHEN; G. Comparative Studies of Copper Tolerance and Uptake by Three Plant Species of the Genus Elsholtzia. Bulletin of Environmental Contamination and Toxicology, v.79, p.53-57, 2007.

XIONG, Z.; LIU, C.; GENG, B. Phytotoxic effects of copper on nitrogen metabolism and plant growth in Brassica pekinensis Rupr. Ecotoxicology and Environmental Safety, v.64, p.273-280, 2006.

YRUELA, I.; ALFONSO, M.; BARÓN, M.; PICOREL, R. Copper effect on the protein compositions of photosystem II. Physiologia Plantarum, v.110, p.551-557, 2000.

YRUELA, I. Copper in plants: acquisition, transport and interactions. Functional Plant Biology, v.36, p.409-430, 2009. 